\title{
MANAGEMENT OF $\beta$-LACTAMASE PRODUCERS THROUGH INFECTION CONTROL MEASURES IN BURN ICU
}

\author{
Nachhatarjit Singh', Kanwardeep Singh'2, Maninder Kaur ${ }^{3}$, Kaminderdeep Kaur ${ }^{4}$, Aruna Aggarwal ${ }^{5}$ \\ ${ }^{1}$ Research Assistant, Department of Microbiology, GMC, Amritsar. \\ ${ }^{2}$ AssociateProfessor, Department of Microbiology, GMC, Amritsar. \\ ${ }^{3}$ Research Scientist, Department of Microbiology, GMC, Amritsar. \\ ${ }^{4}$ Infection Control Nurse, Department of Microbiology, Nayyar Heart Institute \& Super Speciality Hospital, Amritsar. \\ 5 Professor \& HOD, Department of Microbiology, SGRD Medical College.
}

ABSTRACT
BACKGROUND AND OBJECTIVES
Multi-Drug Resistant (MDR) pathogens due to various $\beta$-lactamases are major contributors in increasing morbidity and mortality
rates in Burn Intensive Care Units, ICU. This study is aimed to apply the various infection control measures and to compare the results
of two halves of study and to establish a relation between environment, Health Care Workers (HCWs) and patients regarding
manifestation of nosocomial infection.

\section{DESIGN AND SETTING}

Over a period of three years (June 2010 to June 2013), Clinical, Environment and Health care providers samples from Burn ICU were processed in the Department of Microbiology, Sri Guru Ramdas Institute of Medical Sciences and Research, Amritsar. Organisms were identified by standard microbiological techniques and their antibiotic susceptibility was determined by Kirby Bauer disc diffusion method. The MDR were further tested for various $\beta$-lactamases by Clinical Laboratory Standard Institute (CLSI) disc diffusion method using Ceftazidime and Ceftazidime + clavulanate and Cefotaxime and Cefotaxime clavulanate for Extended Spectrum Beta Lactamases (ESBL), Meropenem and meropenem + EDTA for Metallo Beta Lactamases (MBLs) and 3-Dimensional test for AmpC beta lactamases.

\section{MATERIAL AND METHODS}

307 clinical, 210 environmental and 117 HCWs samples in $1^{\text {st }}$ and 192 clinical, 62 environmental and 92 HCWs samples in $2^{\text {nd }}$ half of study were processed by standard microbiological techniques. After identification all MDR isolates were first screened for ESBL, AmpC and MBL then confirmed by the respective confirmatory tests. Results of two halves were statistically analyzed.

\section{RESULTS}

Infection rate was reduced from $50.16 \%$ to $40.10 \%$ in Burn patients. Culture positivity was reduced from $38.0 \%$ to $27.41 \%$ in environmental and $27.35 \%$ to $7.60 \%$ in HCWs samples. $\beta$-lactamases prevalence in Gram positive was $54.23 \%$ and Gram negative was $60.86 \%$ before and $37.03 \%$ and $54.05 \%$ after interventions.

\section{CONCLUSION}

In addition to the economic burden for antibiotic treatment, it is important to monitor the bacteriology, resistance pattern, antibiotic susceptibility and $\beta$-lactamases production in burn ICU. The development of new agents, strict antibiotic policy and effective infection control measures are paramount in the ongoing battle against multi-resistant organisms.

\section{KEYWORDS}

BICU, MDR, ESBL, MBL, AmpC.

HOW TO CITE THIS ARTICLE: Nachhatarjit Singh, Kanwardeep Singh, Maninder Kaur, Kaminderdeep Kaur, Aruna Aggarwal. "Management of $\beta$-Lactamase Producers Through Infection Control Measures in Burn ICU." Journal of Evolution of Medical and Dental Sciences 2015; Vol. 4, Issue 99, December 10; Page: 16422-16425, DOI: 10.14260/jemds/2015/2434

\section{INTRODUCTION}

Burn patients are at higher risk for local and systemic infections and continue to be the leading cause of death despite of broader spectrum antibiotics.[1] Centers for Disease Control and Prevention (CDC) demonstrated that burn Intensive Care Units (ICUs) have the highest rates of primary blood stream infection in patients with central venous catheters among all ICUs.[2] In developing country like India, delay in arrival in a burn facility from remote villages, lack of early coverage of the wound and sepsis are the most important factors dictating the patient outcome.

Financial or Other, Competing Interest: None.

Submission 18-11-2015, Peer Review 19-11-2015,

Acceptance 02-12-2015, Published 09-12-2015.

Corresponding Author:

Nachhatarjit Singh,

\#1018, Guru Gobind Singh Nagar,

Majitha Road,

Amritsar, Punjab.

E-mail:nachhatarjitsingh@yahoo.com

DOI:10.14260/jemds/2015/2434
Disruption of the skin barrier, large cutaneous bacterial load, the possibility of the normal bacterial flora becoming opportunistic pathogens and severe depression of the immune system causes sepsis in burn patient.[3] results $73 \%$ of deaths. ${ }^{[4]}$ Emerging Multi-Drug Resistant (MDR) pathogens have caused an unexpected rise in burn wound infections, sepsis and associated death worldwide. ${ }^{[5]}$ and have been reported as the cause of nosocomial outbreaks of infection in burn unit. [6,7] Gram-negative organisms cause serious infection in burn patients. ${ }^{[8]}$ extended spectrum beta-lactamases (ESBL), AmpC (Ampicillin resistant) and Metallo beta lactamases (MBL) $\beta$-lactamases producing organisms pose a major problem for treating burn victims. ${ }^{[9,10]}$

The routine susceptibility tests done by clinical laboratories fail to detect $\beta$-lactamases production.[11,12,13] Hence, it is necessary to know the prevalence of $\beta$-lactamases producers in a burn ICU where infections due to resistant organisms are much higher. Information regarding prevalence of organisms in environment and Health Care Workers (HCWs) is also very important. 
There is not enough information from the Indian subcontinent regarding the prevalence of $\beta$-lactamases mediated resistance, environmental sources of pathogens and infection control management in burn ICU. The aim of the present study is to find the prevalence of MDR pathogens in patients and environment and HCWs and to analyze the effect of infection control measures in burn ICU. Infection with $\beta$ lactamases producing pathogens is a cause of concern in burn ICU for many hospitals worldwide. These infections are associated with increased morbidity, mortality and hospital costs. Our aim was to control the infections with multi-drug resistant organism by various control measures and to understand the exact route in which infection travels.

The few studies documented a direct relationship between nosocomial infections and its potential route, which includes environment and health care workers as carriers. Our aim was also in recommending an intervention to decrease the nosocomial infections in ICUs and to check statistically whether the interventions have positive impact in reducing the nosocomial infections with multidrug resistant organisms and antibiotic resistance due to $\beta$-lactamases.

\section{MATERIAL AND METHODS}

A prospective study was conducted over a period of three years (June 2010 to June 2013) and was divided in Preintervention period ( $1^{\text {st }}$ half $)$ and post intervention period $\left(2^{\text {nd }}\right.$ half) in the Department of Microbiology, Sri Guru Ram Das Institute of Medical Sciences and Research Vallah, Amritsar. Clinical, environmental and HCWs samples were collected from Burn ICU of Sri Guru Ram Das Charitable Hospital Valla, Amritsar. All the specimens were processed by standard techniques for isolation and identification. ${ }^{[14]}$ Antimicrobial susceptibilities of the isolates were detected by Kirby-Bauer Standard Disk Diffusion (SDD) method using various antimicrobial agents as per Clinical and Laboratory Standards Institute (CLSI) guidelines. Quality control was achieved by using standard strain of Escherichia coli ATCC 25922.[15]

Gram-negative isolates resistant to third-generation cephalosporin were further tested for ESBL, MBL and AmpC phenotype. ESBLs were detected by the (disc diffusion methods using Ceftazidime and Ceftazidime+clavulanate and Cefotaxime and Cefotaxime+clavulanate discs) for ESBLs and (Meropenem and meropenem+EDTA disc) for MBLs confirmatory method of Clinical and Laboratory Standards Institute (CLSI). Inducible AmpC $\beta$-lactamase was detected by 3D test.[16] Quality control was achieved by using known AmpC positive isolate of K. Pneumoniae ATCC 700603. Metallo $\beta$ lactamase production was detected by Meropenem- EDTA disk test by disc potentiation method. Lactamases in Gram positive isolates were detected by Nitrocefin method. Environment samples were taken by standard swab culturing technique from various sites like wall, floor, bed trolley, monitor, IV stand, etc. Swab from hand, nose, uniform etc. were taken from healthcare providers in Burn ICU. Chi-square test was employed to compare results regarding positive samples before and after intervention. The various infection control measures taken in Burn ICU were:

1. Training of healthcare workers in ICUs for enforcing hand hygiene and sample collection by aseptic techniques.

2. Circulation of MDR data to treating doctors in ICUs.

3. Formulation of Antibiotic policy and circulation of Antibiogram for antibiotic use accordingly.

4. Formulation of disinfection policy.

5. Awareness of ICUs staff to adopt standard precautions and proper hygienic measures to reduce nosocomial infections.

6. Monitoring of microbial load after fumigation in ICUs by strict control over the movement of people and material in ICUs.

\section{RESULTS}

Bacterial isolation was $50.16 \%$ clinical, $38.0 \%$ environmental and $27.35 \%$ in staff before interventions, while it was reduced to $40.10 \%$ in clinical, $27.41 \%$ in environmental and $7.60 \%$ in HCWs after interventions. Level of significant was 0.001 . Similarly, $\beta$-lactamases prevalence was reduced to $46.67 \%$ from $66.67 \%$ in Gram +ve and 58.06\% from 65.49 in Gram -ve isolates as shown in Table 1.

Prevalence of Gram +ve has increased in $2^{\text {nd }}$ half from $3.90 \%$ to $7.81 \%$ in patients, while it decreases from $13.80 \%$ to $11.29 \%$ in environment and from 15.38 to $5.43 \%$ in HCWs. Prevalence of Gram negative isolates was reduced from $65.49 \%$ to $58.06 \%$ in patients, $52.94 \%$ to $40.0 \%$ in environment and $42.85 \%$ to nil in HCWs samples. Methicillin resistant $\mathrm{S}$ aureus prevalence was decreased from $58.33 \%$ to $53.33 \%$ in patient, $27.58 \%$ to $14.28 \%$ in environment and $22.23 \%$ to $20.0 \%$ in staff as shown in Table 2.

Prevalence of Gram -ve isolates decreased from $62.54 \%$ to $32.29 \%$ in patients, $24.28 \%$ to $16.12 \%$ in environment and $11.96 \%$ to $2.1 \%$ in staff in $2^{\text {nd }}$ half after interventions. Pseudomonas was maximum prevailed isolates in patient, environment and staff as shown in Table 3. Among $93 \beta$ lactamases in patient, maximum phenotype detected in $1^{\text {st }}$ and $2^{\text {nd }}$ half was ESBL $32.25 \%$ and $33.34 \%$ respectively followed by others as shown in Table 4 .

\section{DISCUSSION}

The infection of burn wounds with multiple organisms with the super added problem of drug resistance due to presence of $\beta$-lactamases.[17] This necessitates a drug policy by the hospitals for burn patients. Burn wound monitoring requires the study of changing bacterial flora and the antibiotic sensitivity reports. Repeated swab cultures and Antibiogram are advised for proper selection of antibiotics to control sepsis.[18] In present study, we observed that maximum cases of burn infection was with pseudomonas $35.1 \%$, which is similar like other studies.[19] Our study is in contrast to some other studies, especially from developed countries which report S. aureus as predominant organism.

In present study, one of the most striking differences was the prevalence of Klebsiella spp. which is contrary to study conducted in Nigeria.[20,21] where Klebsiella spp. was the most frequent pathogen isolated. No isolate of $\beta$-hemolytic Streptococci was seen, which is in agreement with the previous studies.[22] but contrary to findings in other study.[23]

In our study, pseudomonas aeruginosa was predominant pathogen in patient and environment sample which was the most common cause of burn wound infections in many centers. ${ }^{[24]}$ Many centers from India have also reported the same.[25,26] As similar organism in patient, environment and HCWs were found in our study, an effective infection control policy is required to reduce or eliminate endemic pathogenic and antibiotic resistant organisms. Effective policy helps to prevent the establishment of antibiotic-resistant organisms as the predominant nosocomial flora of the burn unit and prevent cross-contamination. ${ }^{27]}$

High prevalence $55.31 \%$ of $\beta$-lactamases was seen in our study. This may be due to the treatment of patients empirically by clinicians. Thus study suggests the empirical therapy policy in hospital, which should be based not only on the sensitivity pattern of organisms, but also on the basis of presence of various $\beta$-lactamases.

\section{CONCLUSIONS}

Overcrowding, inadequate sterilization and disinfection practices, cross contamination of the environment, lack of isolation facilities, inadequate hand washing and barrier nursing are some of the reasons for high cross infection and sepsis rates in burn ICU in many developing countries. ${ }^{[28]}$ 
The infection control programme in burn ICU requires strict compliance with a number of environmental control measures that include strictly enforced hand hygiene and the universal precautions. Health care workers must be gowned (Including use of disposable or reusable gowns and disposable plastic aprons to prevent soiling of health care workers' clothing during wound care procedures) and gloved at each entry to the burn ICU. During the study, it was also observed that large number of Gram-negative bacteria and emerging pathogens such as Pseudomonas, Klebsiella spp. and Citrobacter species showed resistance to some disinfectants and antiseptic solutions. Hence, study also suggests the disinfection and sterilization and monitoring practices in burn ICU.

Same strains of microbes were isolated from patients, environment and HCWs. This concludes that microbes are transferring from one source to other, i.e. from environment to HCWs and to patients and vice versa. Awareness and knowledge of the extent of the nosocomial infection, its causes, modes of transmission, and types of isolates help the health care providers to make effective infection control policy. During study it was observed that the infection control policy applied to control the sources of infection, preventing cross transmission with proper hand hygiene and implementation of antibiotic policy was effective in decreasing the nosocomial infections and antibiotic resistance in burn ICU. In some countries, there is antibiotic restriction policy that means Infectious Disease physician should give justification for prescription of antimicrobials (Restrictive education antibiotic stewardship programme). Such like antimicrobial restriction policy should be implemented in our country also.

\section{REFERENCES}

1. Bang RL, Gang RK, Sanyal SC, et al. Burn septicemia: an analysis of 70 patients. Burns 1998;24:354-361.

2. Tancheva D, Hadjiiski O. Effect to early nutritional support on clinical course and septic complications in patients with severe burns. Ann Burns Fire Disasters 2005;18:74-79.

3. Jones WG, Minei JP, Barber AE, et al. Bacterial translocation and intestinal atrophy after thermal injury and burn wound sepsis. Ann Surg 1990;211:399-405.

4. Agnihotri N, Karlowsky JA, Jones ME, et al. Prevalence and antimicrobial susceptibilities of bacteria isolated from blood cultures of hospitalized patients in the United States in 2002. Ann Clin Microbiol Antimicrob 2004;3:3-7.

5. Gupta V, Joshi RM. Aerobic bacterial isolates from burn wound infections and their antibiograms-a five year study. Burns 2004;30:241-243.

6. Mason Jr AD, McManus AT, Pruitt BA Jr: Association of Burn Mortality and Bacteremia: a 25-Year Review. Arch Surg 1986;121:1027-1031.

7. Richards C, Emori TG, Edwards J, et al. Characteristics of hospitals and infection control professionals participating in the National Nosocomial Infections Surveillance System 1999. Am J Infect Control 2001;29:400-403.

8. Gallagher JJ, Williams-Bouyer $\mathrm{N}$, Villarreal $\mathrm{C}$, et al. Treatment of infection in burns. In: Herndon DN, editor. Total Burn Care. 3rd. Philadelphia: WB Saunders; 2007. pp. 136-176.

9. Pfaller MA, Jones RN. MYSTIC (Meropenem Yearly Susceptibility Test Information Collection) results from the Americas: resistance implications in the treatment of serious infections. J Antimicrob Chemother 2000;46:2537.
10. Goossens H. MYSTIC (Meropenem Yearly Susceptibility Test Information Collection) results from Europe: comparison of antibiotic susceptibilities between countries and centre types. J Antimicrob Chemother 2000;46:39-52.

11. Jerestin BH, Vandana Agarwal Pathat M. Extended spectrum-lactamases mediated resistance to third generation cephalosporins in Klebsiella pneumoniae in Nagpur, Central India. Indian Journal Med Res 1997;105:158-161.

12. Mathur P, Kapil A, Das B, et al. Prevalence of extended spectrum beta lactamase producing gram negative bacteria in a Tertiary Care Hospital. Indian J Med Res 2002;115:153-157.

13. Chaudhary U, Aggarwal R. Extended spectrum $\beta$ lactamases and emerging threat to clinical therapeutics. Indian J Med Micrbiol 2004;22:75-80.

14. Abigali S, Mathur, Jesudasan MV. Ceftazidime resistance among Klebsiella pneumoniae in South India. Indian Journal Med Research 1995;120:53-55.

15. National Committee for Clinical Laboratory Standards (2000). Performance standards for antimicrobial susceptibility testing-Ninth information supplement: M100-S10. NCCLS. Wayne, A, USA.

16. Manchanda V, Singh NP. Occurence and detection of AmpC $\beta$ - lactamases among gram-negative clinical isolates using a modified three-dimensional test at Guru Tegh Bahadur Hospital, Delhi, India. J Antimicrob Chemother 2003;51:415-418.

17. David LM, Brown DF. Detection of Beta lactamasemediated resistance. J Antimicrobiol Chemother 2001;48(1):59-64.

18. Bairy I, Shivananda PG. Aerobic bacterial flora of burn wound infection. Indian J Surg 1997;59:215-218.

19. Agnihotri N, Gupta V, Joshi RM. Aerobic bacterial isolate from burn wound infections and their antibiograms- a fiveyear study.

Burns 2004;30:241-243.

20. Ozumba UC, Jiburum BC. Bacteriology of burn wounds in Enugu, Nigeria. Burns 2000;26:178-180.

21. Kehinde AO, Ademola SA, Okesola AO, et al. Pattern of bacterial pathogens in burn wound infections in Ibadan, Nigeria. Ann Burns Fire Disasters 2004;18:5-12.

22. Sharma S, Hans C. Bacterial infection in burn patients: a three years study at RMI Hospital, Delhi. J Commun Dis 1996;28:101-106.

23. Sandhir RK, Tiwari IN, Goel A. Management of electrical injuries of the abdomen. Burns 1992;18:253-255.

24. Ekrami A, Kalanter E. Bacterial infections in burn patients at a Burn Hospital in Iran. Indian J Med Res 2007;126:541544 .

25. Revathi G, Puri J, Jain BK. Bacteriology of burns. Burns 1998;24:347-349.

26. Shahid M, Malik A. Resistance due to aminoglycoside modifying enzymes in Pseudomonas aeruginosa isolates from burns patients. Indian J Med Res 2005;122:324-329.

27. Weber J, McManus A. Infection control in burn patients. Burns 2004;30:A16-24.

28. Taneja N, Emmanuel R, Chari PS, Sharma M. A prospective study of hospital-acquired infections in burn patients at a tertiary care referral center in North India. Burns 2004;30:665-669. 


\begin{tabular}{|c|c|c|c|c|c|c|}
\hline & \multicolumn{2}{|c|}{ Patients } & \multicolumn{2}{|c|}{ Environment } & \multicolumn{2}{|c|}{ HCWs } \\
\hline & $1^{\text {st }}$ half & $2^{\text {nd }}$ half & $1^{\text {st }}$ half & $2^{\text {nd }}$ half & 1st half $^{\text {st }}$ & $2^{\text {nd }}$ half \\
\hline Bacterial isolation & 50.16 & 40.10 & 38.09 & 27.41 & 27.35 & 7.60 \\
\hline Gram +ve & 3.90 & 7.81 & 13.80 & 11.29 & 15.38 & 5.43 \\
\hline Gram -ve & 62.54 & 32.29 & 24.28 & 16.12 & 11.96 & 2.1 \\
\hline $\begin{array}{l}\beta \text {-lactamases } \\
\text { prevalence }\end{array}$ & 65.58 & 54.54 & 52.5 & 35.29 & 46.87 & 14.28 \\
\hline Gram +ve & 66.67 & 46.67 & 51.72 & 28.57 & 50.0 & 20.0 \\
\hline Gram -ve & 65.49 & 58.06 & 52.94 & 40.0 & 42.85 & 0.0 \\
\hline
\end{tabular}

\begin{tabular}{|c|c|c|c|c|c|c|}
\hline & \multicolumn{2}{|c|}{ Patients } & \multicolumn{2}{c|}{ Environment } & \multicolumn{2}{c|}{ HCWs } \\
\hline & $\mathbf{1}^{\text {st }}$ half & $\mathbf{2}^{\text {nd }}$ half & $\mathbf{1}^{\text {st }}$ half & 2 $^{\text {nd }}$ half & $\mathbf{1}^{\text {st }}$ half & 2 $^{\text {nd }}$ half \\
\hline MS S aureus & 41.66 & 46.67 & 48.27 & 28.57 & 44.45 & 40.0 \\
\hline MR S aureus & 58.33 & 53.33 & 27.58 & 14.28 & 22.23 & 20.0 \\
\hline CONS & -- & -- & 24.13 & 57.14 & 33.34 & 40.0 \\
\hline $\begin{array}{c}\text { Total Gram +ve } \\
\text { Isolates }\end{array}$ & $\mathbf{3 . 9 0}$ & $\mathbf{7 . 8 1}$ & $\mathbf{1 3 . 8 0}$ & $\mathbf{1 1 . 2 9}$ & $\mathbf{1 5 . 3 8}$ & $\mathbf{5 . 4 3}$ \\
\hline \\
Table 2: Prevalence (\%) of Gram +ve Bacterial Isolates in Patient, \\
Environment and HCWs Before and After Interventions \\
\hline
\end{tabular}

\begin{tabular}{|c|c|c|c|c|c|c|}
\hline & \multicolumn{2}{|c|}{ Patients } & \multicolumn{2}{c|}{ Environment } & \multicolumn{2}{c|}{ Staff } \\
\hline & $\mathbf{1}^{\text {st }}$ half & $\mathbf{2}^{\text {nd }}$ half & $\mathbf{1}^{\text {st }}$ half & $\mathbf{2}^{\text {nd }}$ half & $\mathbf{1}^{\text {st }}$ half & $\mathbf{2}^{\text {nd }}$ half \\
\hline E coli & 25.35 & 24.19 & 19.90 & 20.0 & 21.42 & 50.0 \\
\hline Klebsiella & 10.47 & 11.29 & 31.37 & 30.0 & 28.57 & 00 \\
\hline Pseudomonas & 38.73 & 37.09 & 49.01 & 50.0 & 35.71 & 50.0 \\
\hline Citrobacter & 9.15 & 11.29 & Nil & Nil & 14.28 & Nil \\
\hline Acinetobacter & 7.04 & 8.06 & Nil & Nil & Nil & Nil \\
\hline Enterobacter & 4.22 & 6.45 & Nil & Nil & Nil & Nil \\
\hline Proteus & 3.52 & 1.61 & Nil & Nil & Nil & Nil \\
\hline $\begin{array}{c}\text { Total Gram -ve } \\
\text { Isolates }\end{array}$ & $\mathbf{6 2 . 5 4}$ & $\mathbf{3 2 . 2 9}$ & $\mathbf{2 4 . 2 8}$ & $\mathbf{1 6 . 1 2}$ & $\mathbf{1 1 . 9 6}$ & $\mathbf{2 . 1}$ \\
\hline \multicolumn{7}{|c|}{ Table 3: Prevalence (\%) of Gram -ve Bacterial Isolates in Patient, } \\
\hline
\end{tabular}

\begin{tabular}{|c|c|c|c|c|c|}
\hline \multirow[t]{2}{*}{ Sl. No. } & \multirow[t]{2}{*}{ Phenotype } & \multicolumn{2}{|c|}{$\begin{array}{c}1^{\text {st }} \text { half } \\
\text { (Before Interventions) }\end{array}$} & \multicolumn{2}{|c|}{$\begin{array}{c}2^{\text {nd }} \text { half } \\
\text { (After Interventions) }\end{array}$} \\
\hline & & No. & $\%$ age & No. & $\%$ age \\
\hline 1 & ESBL & 30 & 32.25 & 12 & 33.34 \\
\hline 2 & MBL & 26 & 27.95 & 10 & 27.77 \\
\hline 3 & AmpC & 10 & 10.75 & 4 & 11.12 \\
\hline 4 & Carbapenemase & 13 & 13.97 & 4 & 11.12 \\
\hline 5 & $\mathrm{MBL}+\mathrm{AmpC}$ & 5 & 5.37 & 4 & 11.12 \\
\hline \multirow[t]{2}{*}{6} & ESBL+MBL & 9 & 9.67 & 2 & 5.56 \\
\hline & Total & 93 & & 36 & \\
\hline & $\begin{array}{l}\text { 4: Prevale } \\
\text { Gram Nego }\end{array}$ & $\begin{array}{l}\text { \%) } 0 \\
\text { Isola }\end{array}$ & and $A$ & sof $\beta$ & $\begin{array}{l}\text { ases in } \\
\text { s }\end{array}$ \\
\hline
\end{tabular}

